International Journal of Instruction e-ISSN: 1308-1470 • www.e-iji.net

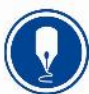

October $2018 \bullet$ Vol.11, No.4

p-ISSN: 1694-609X

pp. $545-564$

Received: $15 / 04 / 2018$

Revision: $27 / 06 / 2018$

Accepted: 30/06/2018

\title{
Traditional and Inquiry-Based Learning Pedagogy: A Systematic Critical Review
}

\author{
Bilal Khalid Khalaf \\ Language Academy, UTM, Malaysia,bk1142015@gmail.com
}

Zuhana Bt Mohammed Zin

Dr., Language Academy, UTM, Malaysia

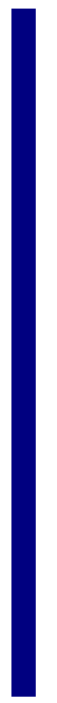

Learning methodologies have been studied extensively for more than five decades. While traditional learning model was previously dominant method in the field of learning, the early 1970s saw a wide range of reforms in educational fields supported by new technologies that facilitate the change from a teacher to a student-centred model. However, these reforms are still limited regarding efficiency. This study constitutes a systematic and critical review of the two dominant learning models, traditional and inquiry-based learning. While, traditional learning is supposed to increase learners' outcomes and keeps them active during the learning process, it has been widely asserted that inquiry-based learning increases learners' knowledge and skills. This review is based on fortythree empirical studies reported in the literature between 2002 and 2017. It identified a number of important drawbacks to both traditional and inquiry-based learning in the previous works. This review had analysed and evaluated critically the advantages and disadvantages of both learning methods. A gap was found between the current learning methods and the expectations of our educational systems in developing learner's knowledge and skills. Thus, this review concludes that a new pedagogical design is necessary to emphasises the advantages and negates disadvantages of both learning models.

Keywords: traditional learning, inquiry-based learning, learners, teachers, outcomes, confidence

\section{INTRODUCTION}

The process of knowledge acquisition is carried out by a particular method that theorists called learning (Catford, 1965). Learning process is still somewhat of a mystery to researchers. Learning is considered a primary function of the brain. Researchers note that nobody before the 1980s was aware of what happens in the brain during the process of learning; For instance, Mona Baker (2011) refers to the human brain as a 'black box'. However, previous studies tend to be based on the outcomes of learners (Baker, 2011).

Citation: Khalaf, B. K., \& Zin, Z. B M. (2018). Traditional and Inquiry-Based Learning Pedagogy: A Systematic Critical Review. International Journal of Instruction, 11(4), 545-564. https://doi.org/10.12973/iji.2018.11434a 
Modern scholars have attempted to investigate the learning process in terms of how it leads to certain outcomes by understanding and describing this process (Kiraly, 2017).

Various approaches have been adopted to define the learning process, with one earlier definition by Knowles (1973) who described learning as the process of gaining knowledge and expertise. Mayer (1987) claimed that learning could be described as a relatively permanent change in a person's knowledge or behaviour due to a particular experience. Brown, Roediger, and McDaniel (2014) described the process of learning and retrieving knowledge as "Acquiring knowledge and skills and having them readily available from memory so you can make sense of future problems and opportunities" (p.2). All approaches and scholars have shared the central idea that learning involves acquiring knowledge and developing skills for solving future problems.

A number of theories existed to explain the complex nature of the learning process. Behaviourism was the first theory to contribute to the explanation of the process of learning from the early day of Aristotle and Skinner, which adopted a traditional learning model as the prominent model of learning for centuries. In traditional learning, the teacher is the dominant source of knowledge in the class; teachers are the senders of knowledge, and students are the receivers (Rashty, 1999). Many educators believed that in traditional learning students do not have the opportunity to take an active part in the learning process unless their teacher asks them to complete a task or ask them a question. The knowledge presented by teachers is usually unchallengeable, and students have to accept it (María \& Luisa, 2016).

Traditional learning produces active and non-active learners as result of its conceptualization of the learning process. Traditional behavioural classes do not favour active engagement of learners in the learning process, but rather focus on the behavioural impacts of immediate context and the teacher's role on learners. However, TL which is influenced by behaviourism theory has received criticism by cognitivist advocates who believed learners' involvement in learning process is more meaningful in developing learner's skills, experience and knowledge (Dorier \& Maab, 2012). Cognitive and constructive schools projected various models in the field of learning. Inquiry-based learning was one of the models that challenged the concepts of traditional learning. Elements of this model have their origins from around 1911 (Pi, 2010).

The inquiry-based model combines both learning and practise. Currently, many universities have adopted inquiry-based model since 1970s in Europe and United States; For example, Hampshire College in the United States has used an inquiry-based curriculum since its founding in 1970. Furthermore, McMaster University adopted IBL for over twenty years (McMaster University, 2007). Traditional and inquiry-based learning had been implemented in the field of learning widely in the field of learning and scholars employed them in a large number of successful studies, which are prominent among western educators in western countries, as shown in appendix (A). Therefore, the current review has been driven by the following inquiries:

I. To what extent are traditional and inquiry-based learning effective pedagogical models in developing learners' background knowledge and skills? 
II. What evidence is there in the literature to show the drawbacks of traditional learning? What are those drawbacks?

III. What are the challenges and drawbacks discussed in the literature for implementing an inquiry-based model?

IV. What evidences are there in the literature that identify the triangulated relationship between the teacher, learner and learning model in class that validate the reliability of learning methods?

\section{METHOD}

The current literature review implements a systematic approach to analyse critically of two dominant learning methods' pedagogies and to identify and evaluate their implications on learners' cognition and outcomes. Dixon-Woods (2010) defined systematic literature review as "a scientific process governed by a set of explicit and demanding rules oriented towards demonstrating comprehensiveness, immunity from bias, and transparency and accountability of technique and execution" (p.332). It is the process of collecting qualitative and quantitative data from the relevant literature in order to compare and evaluate the ability of a certain phenomenon to address current issues (Borenstein, Hedges, Higgins, \& Rothstein, 2009).

The process of systematic review is characterized by some criteria that are used to narrow the scope of a review (Higgins \& Green, 2009). The studies selected for this review involve quantitative and a few qualitative studies based on the inclusion criteria developed at the beginning of the review process. These criteria are the standards for judging the weight of evidence in the studies included in this review. Table.1 explains the inclusion criteria in detail Gough (2007).

Table.1

Literature inclusion criteria

\begin{tabular}{cll}
\hline \multicolumn{1}{c}{ No. } & \multicolumn{1}{c}{ Criteria } & \multicolumn{1}{c}{ Description } \\
\hline 1. & Topic & The literature must relate directly to traditional and inquiry-based learning. \\
\hline 2. & Period & $\begin{array}{l}\text { Studies published between } 2002 \text { and 2017, the date for the last meta- } \\
\text { analysis related to the subjects under investigation. }\end{array}$ \\
\hline 3. & Research Base & $\begin{array}{l}\text { Literature should include only empirical studies of both quantitative and } \\
\text { qualitative. }\end{array}$ \\
\hline 4. & Transparency & $\begin{array}{l}\text { The method of research in previous studies must be explicit in terms of } \\
\text { sample size, instrument and analysis. }\end{array}$ \\
\hline 5. & $\begin{array}{l}\text { Reliability } \backslash \\
\text { Validity }\end{array}$ & $\begin{array}{l}\text { The outcomes of literature studies must be valid and reliable according to } \\
\text { the type of the study and publication indexed. }\end{array}$ \\
\hline
\end{tabular}

The first stage was the development of the inclusion criteria shown in Table.1, to ensure that the literature systematically reviewed. Studies that did not match those criteria were excluded from the review. The second stage involved the search for related studies in online databases and hard copies of books and journals using the keywords that embodied the topic of current review. The studies addressed in this literature were considered as per the criteria of inclusion. The initial search found two hundred thirtyfive related studies that meet the requirement of the first stage of the inclusion criteria. 
The third stage involved a review of the abstracts of the studies to evaluate the search outcomes. A total number of 117 relevant works include meta-analyses and surveys in the literature. During the fourth stage, a broader investigation of relevant works was conducted to identify the sample sizes, methodologies and outcomes of the studies. Only, forty-three studies matched the inclusion criteria of the current review. Subsequently, an analysis of relevant works was carried out to build a critical picture of the current review, which identified a prominent element of traditional and inquirybased learning methods in the previous literature. Finally, conclusions were drawn based on the analysis of the studies that identified the gap addressed and validated the inquiries of the current review. Figure. 1 shows the review stages.

Systematic Literature Review
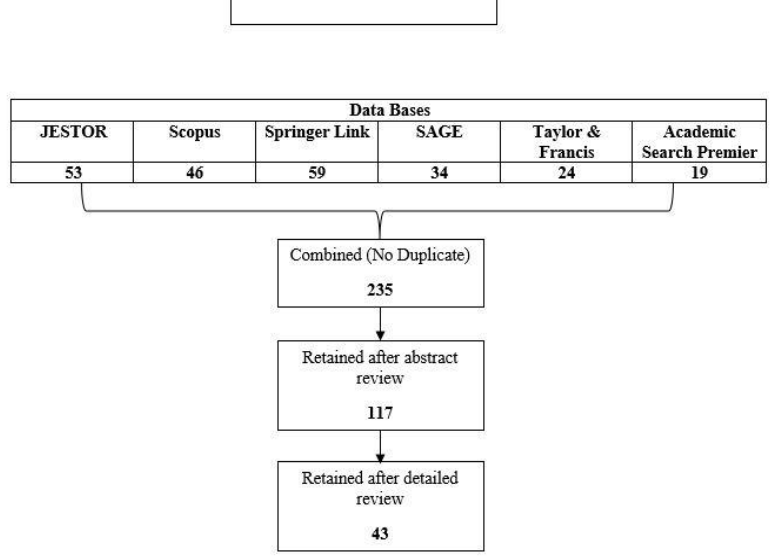

Figure 1

Review stages

\section{TRADITIONAL AND INQUIRY-BASED LEARNING}

Researchers have investigated the term learning from the beginnings of the behaviourism to the current date. They have tried to understand and explain the complicated nature and process of earning to identify required elements of success. The origins of those investigations dated back to famous theorists such as Socrates (468-399 B.C.), Plato (427-347 B.C.) and Aristotle (384-322 B. C.) Austin, Orcutt, and Rosso (2001), who are considered to be the founders of theories that have attempted to explain the complicated, and dynamic process of learning. Modern scholars have described learning as "learning is contested, and that assumptions that people make regarding its nature and where it takes place also varies widely" (Schoenfeld, 1999, p. 7).

The debate on understanding and enhancing the learning process has repeatedly been raised over time. The development of human lifestyle and introduction of new technologies played a prominent role in the development of learning models. Theorists designed some approaches to identify the essential elements of this process. All learning models or approaches are based on theoretical concepts. There are three dominant 
theories of learning: (a) behaviourism (studying and analysing human behaviours), (b) cognitivism (knowledge constructed by mental cognition), and (c) constructivism (learners construct the knowledge during the learning process).

Theoretical perspectives are considered to be the foundation for the implementation of effective learning in the classroom. In the current review, traditional learning, which was underpinned by behaviourism and inquiry-based learning, which is underpinned constructivism are the key models of learning under investigation. Johnson (1991) and Hall (2002) classified the process of traditional learning in two stages: encoding and decoding. These stages are followed by assessments of the knowledge acquired, which is typically characterised by the term examination in order to evaluate the outcome of the students' performance. The most prominent criterion of traditional learning proposed by Rashty (1999) is that teachers always talk more than the students in the traditional classroom. Furthermore, the traditional learning process can be characterized as whole class participation, i.e. there are no individual or group activities (Rashty, 1999).

Traditional teachers assume the overriding authority and responsibility in the classroom because they believe that they know the students' needs and the classrooms should strictly follow specified time and place (Austin et al., 2001). Finally, the teachers deliver their lessons according to the study programme for an existing curriculum, which ignores the gradual development of students' knowledge (Rashty, 1999). Moreover, Entwistle and Tait (1995) criticised examination in traditional learning as an obstacle to students' education to achieve a deeper understanding of knowledge. Examination leads to a superficial learning approach, i.e. students' memorised knowledge rather than understand it (Biggs, 1996). Due to this situation, traditional learners encounter considerable challenges and drawbacks in the fields of practical science and the problem-solving process (Entwistle \& Tait, 1995).

Bereiter and Scardamalia (1993) claimed that the current educational models do not fulfil the expectations of our educational systems designs as if its purpose to produce non-expert rather than expert learners (Bereiter \& Scardamalia, 1993). Scholars have argued that the traditional method seems to consume time and efforts in limited development in learners' knowledge more than what does it supposed to offer (Penrose \& Geisler, 1994). This argument related to the surveys in the literature on learners' knowledge, skills and professionalism. The criteria of traditional learning leave it open to extensive criticism and raise the necessity for a better substitute learning methodology. Since the 1970s, there have been calls for reform of the old traditional methods of teacher-centred learning into practical methods that are more focussed on learners.

Researchers such as Greenberg (1987), Dewey (1993), Mitra (2007), and Russell and Greenberg (2008) have argued that the idea of traditional learning focusses on teaching rather than learning. Those scholars noted that in every minute of teaching, the assumption that the learners acquire a minute of learning is mistaken. Thus, the change from teacher to student-centred learning was in favour of a new trend of constructivists who indicated the importance of practice in learning. The presence of cognitivism theorists paved the way for constructivists to carry out this change. The rapid global 
movement towards new technologies assisted the transition from descriptive cognitive into critical constructive.

After a wide criticism on the nature and outcomes of traditional learning. it is claimed that inquiry can overcome the drawbacks that scholars addressed in traditional learning (Barrow, 2006). The list of inquiry definitions is long because the differences in opinions and conceptualization on this model of learning. Inquiry-based learning is described as a strategy adopted by learners in the process of learning as a similar manner to professional scientists for constructing a new specific knowledge (Keselman, 2003). Furthermore, Pedaste and Sarapuu (2006) defined inquiry-based learning as the process of problem-solving for some issues as well as developing learners' problem-solving skills. Other scholars noted that inquiry is the process of testing a proposed hypothesis and evaluating the findings of the associated experiments or observations (Pedaste, Mäeots, Leijen, \& Sarapuu, 2012).

A further understanding of the nature of inquiry-based learning requires better clarification as to its defining criteria. Dewey (1993) illustrates the main features of inquiry learning: firstly, learners' engagement in discussions; second, learners suggest certain evidence and give this evidence a certain priorities; third, learners formulate explanations from available evidence; fourth, learners connect explanations to scientific knowledge and theories; and finally, learners communicate and explain their findings. The National Research Council (2000) noted similar criteria with regards to learners' engagement and suggested evidence based on priorities. In addition, learners formulate explanations from evidence and connect them to scientific knowledge and theories. Finally, they communicate and explain their findings.

The role of the inquiry method is to offer supportive evidence and explanations for natural phenomena. Sampson, Grooms, and Walker (2011) illustrate this in their article Argument-Driven Inquiry. One of the practical facts on the importance of implementing inquiry-based learning especially in science classes was presented by United States National Research Council. The Council (2000) claimed that three main reasons drive the necessity for implementing inquiry-based learning in classes. First, it can change and improve students' behaviour and skills about understanding in a practical manner. Second, learners need greater engagement in reading, writing, and participating in critical discussions as they learn. Finally, it is favourable to encourage students to participate in the critical argument, which is represented by their explanations for observed phenomena supported by logical reasoning.

Thus, the nature of inquiry-based learning indicates that learning and knowledge are evaluated on an ongoing basis. The initial performance of inquiry-based learning in the educational process made clear that it could not be challenged regarding improving educational systems. Therefore, researchers such as Gibson and Chase (2002) describe it as the proper method for teaching in the scientific method. The implementation of this method requires effort and training on the part of learners to make them properly aware for using of this methodology. This represents an obstacle to many teachers who are still striving to build a shared understanding of what science as inquiry actually means (Keeley \& Eberle, 2008). 
A vast number of studies have described the nature of inquiry-based learning, as supported by a wide range of examples (see, for example, Weaver (1989), Bateman (1990), Alford (1998), and Lee (2004). The studies in the field of inquiry are dominated by scholars who advocate inquiry and encourage others to adopt this learning approach. This can allow for the possibility of debate into the first step of learning, especially in second language or cultural knowledge development. How can we formulate welltrained and skilled learners via a well-modified learning model? What learning method would properly fit both scientific and social fields of knowledge?

\section{LIMITATIONS OF TRADITIONAL LEARNING}

Studies in the literature indicated that students who adopt traditional learning in their education undergo some drawbacks, ultimately leading to the failure of the learning process. Thus, scholars have investigated other learning models that might fulfil the requirements of the learning process and allow for the acquisition of better learning outcomes. These drawbacks are predominantly related to factors such as learners' knowledge, skill improvement, competence, learners' performance and outcomes. The literature gives details of these drawbacks in practical investigations. It contains studies based on large sample sizes to improve its validity and reliability.

The main drawback was that of limited development of learners' background knowledge. An experiment that was undertaken by Olk (2003) explored the role of traditional learning in implementing cultural knowledge and its role on German learners to study their performance. The study recruited 19 university students who were asked to translate an English article for publication in a German magazine. The study showed a limited knowledge on the part of participants to understand and deal with cultural concepts that inevitably led the students using inappropriate translation strategies of translation. Noticeably, Olk's work identified other drawbacks in the traditional model during translation practice. Those drawbacks were related to participants' competence and skill during translation tasks. The dominant role of traditional teachers was the reason for these poor outcomes outside the class in their homework. Undoubtedly, the teacher's role in traditional learning can be recognised as a principal element in the learning process. This may invoke further criticism to the nature of this exercise without describing the role of background knowledge and what participants learned in class. Olk concluded that traditional learning did not fulfil the requirements of situations encountered outside class.

The limitations in students' outcomes and performance during the learning process were the dominant criteria characterizing traditional learning. Farkas (2003) conducted a quantitative study that consisted of 105 students classified into two groups: a traditional or control group, and an instructional group. This study compared the role of traditional and other instructional models in developing learners' performance and outcomes. The design of the study allowed the instructional group to choose the learning method they mastered, while the control group was taught traditionally. This point was a central argument in other studies. Regarding knowledge and learners' skill development, Farkas (2003) identified lower levels of knowledge development amongst traditional learners, while other instructional learners had higher acquisition for knowledge and 
performance. This was reflected in the outcomes found in the study. However, the statistical outcomes of the study supported the implication of other instructional methods rather than traditional in terms of effectiveness. These findings advocate the use of an instructional model that fit current curriculums, rather than wasting time and efforts in the traditional model.

In another context for the evaluation of the development of traditional learners' knowledge, Badawi (2008) investigated Arabic idiomatic expressions by examining the capabilities of Saudi EFL students in translating cultural expressions. The study evaluated the role of traditional learning in developing students' knowledge and participants' awareness of the use of translation strategies. It aimed to determine how traditional learning could affect learners' choice of translation strategies, and how this choice might enhance the outcomes of the task. The study consisted of 43 undergraduate students in their last year of English language studies, adopted a mixed mode of data collection and analysis in cultural-based translation tasks using the thinking-aloud method and a questionnaire to find the strategies that students adopted to form their translations. Learners' performances and awareness of the task were investigated, which showed a relatively poor performance amongst participants. Badawi (2008) added that the learning method and surrounding context affected the outcomes. This created a potential gap in the knowledge between students' skills in processing data and their outcomes. Although Badawi's study did not consider the role of intra-cultures factors within the same language Arab region, it revealed the situation in most Arab countries in terms of second-language learning.

Another quantitative study carried out by Alousque and Negro (2010) found that studying idiomatic expressions required background knowledge to be adequately understood. The primary challenges identified in the study were translating cultural items and the variety of translation strategies that students adapted to convey cultural meanings. The challenges that participants in the study encounter were a result of the absence of cultural knowledge that traditional learners were not able to acquire from their teachers or develop with colleagues. Furthermore, Alousque's study focussed on students' use of translation strategies during the translation process without considering the cognitive process for developing selection skills in those strategies. The study recommended developing learners' cultural knowledge by incorporating cultural practices in classes that traditional learning method could not allow.

The context was used as a tool for facilitating cultural translation tasks by traditional learners. Khalaf (2014) argued that context played a prominent role at the intracultural level within the Arabic language and the translators' choice for suitable translation strategy as applied to in the target culture. Khalaf stated that "both learning culture and the use of context pave the way for translators to achieve a successful translation product" (Khalaf, 2014, p. 85). This study indicated a gap in the knowledge made available in traditional classes that traditional learning translators could not bridge. This was due to the limited role of traditional learning in developing cultural experience and knowledge of learners as previously shown. The study identified that traditional learners had relatively low confidence with their work. 
Recently, Hussain and Khuddro (2016) commented on the effects of traditional learning in developing learners' knowledge and competence. The role of cultural relevance in those expressions and translators skills was deemed to be important to bridge the gap between various cultures. Their work attempted to reproduce similar effects for source text in the target culture by implementing the theory of relevance. It concluded that communicative success in translation could be achieved by the interaction between the surrounding context and the semantic interpretation rooted in the proper orientation of human recognition. This work highlights the nature of memorization that characterized traditional learning, which is considered a drawback to the long-term practice of learning.

Scholars in the field of learning concluded that the current traditional method of learning is not effective any more in the educational field (Kiraly, 2017). Kiraly hypothesised that a collaborative project translation might constitute a reasonable substitution for the traditional model in highlighting the lack of traditional learners' knowledge and competence during translation. This study dealt with bridging the knowledge gap in translator's education through collaborative project work in translating material from English to German, first individually and later in a team environment. Kiraly's work was based on the factors of time, competence, technical limitations and skill in undertaking this work. The outcomes showed noticeable challenges encountered by learners in traditional classes in overcoming the various challenges associated with translation unless they worked in a group environment or team. The work addressed the necessity of changing from traditional learning concepts by highlighting the importance of practice and teamwork in education to develop and improve learners' skills and competence. This work was in favour of implementing a more practical method of learning, such as the inquiry-based model, after the extensive criticism of the traditional model.

Finally, in terms of literacy, learners' ability to interact in the classroom and perform 'recall' task does not mean they are mastering academic literacy (Cruz \& Duff, 1997). This process of recall will not stay in learners' memory because they are performing rather than learning. Gormally, Brickman, Hallar, and Armstrong (2009) state that learners' participation in negotiations and discussions inside classes will increase their literacy and develop their social, cultural and linguistic knowledge. Such approaches were not adopted in traditional classes. However, the previous works and many other studies identified the drawbacks of the traditional method. In conclusion, the literature identified various drawbacks to the traditional learning model. Those drawbacks are manifest in the limited development of knowledge, skills, competence, and the performance of traditional learners as accompanied by minimal outcomes. This method of learning is mostly based on teachers being the dominant aspect of the learning process. The conceptualization of a cognitive theory of learning has introduced the field of learning to allow for further involvement in the learning process and paved the way for the introduction of a constructive approach of learning. The following reform suggests a new practical model through which to develop learners' knowledge and skills. 


\section{NEW TREND OF INQUIRY LEARNING}

A reform in learning methods started after investigating the drawbacks of traditional learning in developing learners' knowledge, cognition and outcomes. Extensive debates among academic scholars that started between 1965 and 1975 and continued until 2003 concluded various methods that might be introduced into the field of learning. All learning models were tested and implemented for specific educational requirements in particular fields of knowledge. It was noted that new technologies did not integrate with the previous traditional method of learning in generating the most beneficial outcomes for cognitive processing (Schauble, Glaser, Duschl, Schulze, \& John, 1995). The inquiry-based learning model was the best learning method that could be incorporated to fit this development.

The American National Research Council (2007) refers to inquiry-based learning as a means of constructing knowledge through collaborative and communicative processes. This method, as implemented in science classes, is more representative of collaborative enterprises than social sciences. Learners are encouraged to develop and inspire teamwork to reach decisions together through sharing the knowledge. The theoretical foundations of this model are based on the constructive theory of learning, which states that knowledge is constructed by learners (Piaget, 2013). Studies have been carried out in different fields of knowledge to evaluate the efficiency with which inquiry can be implemented as a new learning model.

Gibson and Chase (2002) attempted to assess the impacts of implementing inquiry-based learning on long-term learning and the attitude of middle school students towards learning science. The participants in this study were classified into three groups for comparative purposes. The first group was the control group, who attended a summer camp for developing skills in science using inquiry-based learning. The second group was a non-controlled group who did not attend the summer camp. The third group was the counter group, whose members had been traditionally educated. This study is considered conclusive evidence as to the utility of inquiry in developing learners' knowledge compared to traditional learning.

Gibson and Chase (2002) study was conducted between 1996 and 1997. The study indicated that outcomes for the counter group were lower than the non-controlled group that did not attend the summer camp. This may due to the nature of memorising knowledge in traditional learning and its long-term impact on learners. While the controlled group that attended the summer camp were found to have better outcomes than the non-controlled group. The researchers stated several reasons for this, such as direct laboratory exploration, free participation and breaking the ice between students and teachers that advocated the use of inquiry. The interviews conducted in the study showed that students preferred to directly participate in science classes rather than traditionally learning about science. This would inevitably allow students to ask questions and to participate directly in laboratory exercises. Gibson and Chase (2002) noted that "these findings suggest that when science is taught using inquiry-based approach, students remain interested and become motivated to put more efforts into their studies" (p.694). 
Learners' comprehension widely affected by the application inquiry-based instructions. This affection resulted better development in learners understating and knowledge. This claim approved practically in a study carried out by Van Hook and Huziak-Clark (2008). In this study, the researchers focused on inquiry experiences as a plausible teaching model. The model initially focused on the student's prior knowledge before moving on to hands-on activities and reinforcement from the teacher during learning. The implementation of the inquiry-based model helped students to obtain rapid experience, where the findings of the study validated the effects of hands-on activities on the learning process during the initial stages of learners' education. Inquiry-based learning was validated as a useful model for teaching learners at the university level. Watson (2008) advocated the implementation of inquiry-based learning in higher education. He claimed that teachers' instructions and guidance would assist learners in taking active roles during problem-solving procedures. His claims were demonstrated in a study that compared the performance and outcomes of inquiry- and problem-based learners. Interestingly, inquiry-based learning adopted to allow rapid development of problem-solving skills in particular fields of knowledge such as medicine and other practical applications.

Watson (2008) stated that applying IBL needs for a set of exercises which it could be called learning by doing through applying deeper understanding and critical thinking of the current issue. This shows the relationship between existing knowledge and learners' abilities, the stage of the degree or programme, the temporal scale and group or individual work. Accordingly, Watson's work supported the application of the inquirybased learning approach in higher education classes. He confirmed that inquiry-based practice requires vast amounts of varied information and further participation by students to identify the purpose of learning as the act of doing.

Moreover, Wolf and Fraser (2008) made an explicit comparison between traditional and inquiry-based learning methods based on the learning environment and students' performance. Whilst, the study was concerned with the learning methodology and learner achievements in science classes, it detected a notable difference in the performance of learners during the learning process. Accordingly, their work involved 1,434 students in 71 classes. It indicated a change of more than double the student achievements for those who adopted inquiry-based instructions over traditional methods. The study concluded that inquiry-based learning was an effective method of learning regarding student outcomes and performance towards learning more than traditionalbased method.

The main practical cornerstone in the inquiry-based learning literature was the PRIMAS project conducted by Dorier and Maab (2012), which was run between the years 20072012 in Europe. It was a leading project that advocated the use of inquiry-based learning across Europe. The project advocated the use of inquiry-based learning as a learning method to increase students' interest and achievements in science classes. The project concluded that implementing inquiry-based learning in real teaching environments will inevitably enhance the educational process and develop learners' knowledge. Accordingly, this leads to a further understanding of students' cognition processes and 
interaction with present knowledge regarding evaluating specific outcomes. The project investigated the nature of inquiry-based learning with respect to both teachers' and students' perspectives, and indeed went further to identify the challenges encountered during the application of inquiry-based learning in Europe. The project designed a wellformulated report by professionals on the use of inquiry-based learning and the range of application in European countries. It concluded by advocating the use of inquiry-based learning as the predominant educational method due to its cognitive constructive implications and motivational role in developing leaners' competence and knowledge.

A comparative study of traditional and current prominent teaching approaches was carried out by María and Luisa (2016). They commented on a statement made by Grasha (1996) as to the variety of teaching models used for educational pedagogy and involving students in practice. Their claim was in favour of critical thinking that aims to allow for better outcomes and develop learners' skills and knowledge. María and Luisa (2016) noted that an effective learning model would reinforce teaching, learning, assessment and imply additional resources of knowledge. However, a number of studies advocated the implementation of inquiry-based learning and furthermore, its role in assisting the development of learners' skills and knowledge. After wide application in various fields of knowledge, scholars noticed some issues in the implementation and outcomes of inquiry learners. This argument raises the possibility of investigating and evaluating the impact of inquiry. The following section will include some related studies that have discussed this issue and attempted to summarise the drawbacks of inquiry as a learning model.

\section{CHALLENGES OF INQUIRY AND CRITICAL REFORM}

Scholars hypothesised that an inquiry-based learning model fulfils the drawbacks identified in traditional learning. Inquiry-based learning fulfilled the need for practical involvement of students in the learning process. The application of inquiry-based learning is being increasingly carried out in science classes but is limited in the social sciences. This requires further investigation as to the role of inquiry in social classes. Interestingly, some scholars found that inquiry-based learning could be somewhat limited in its ability to address significant areas of application and practice. However, previous literature has shown the benefits of adopting inquiry-based learning as a new trend in learning. Surveys of instructional practices suggest that its application in a number of science classrooms has been widely embraced in college biology laboratory curricula over the past few years "Reportedly from less than $10 \%$ to almost $80 \%$ of laboratory classrooms at universities in the U.S" (Sundberg, Armstrong, \& Wischusen, 2005 , p. 528). This change demonstrates the efforts that required to promote reform in laboratory education and other fields of knowledge.

Krajcik et al. (1998) recognised that learners encountered difficulties in conducting systematic scientific investigations during the implementation of inquiry-based learning in classrooms. Later work by Walker (2007) classified these challenges into "problems related to the school system, problems related to the resources, and problems related to the individual teacher" (Walker, 2007, p. 27). Similar difficulties were addressed by the PRIMAS project in Europe (2013), which corroborated the findings of Krajcik et al. 
(1998) and Walker (2007). These studies provided an explicit classification of the challenges encountered by inquiry-based learners during learning practice.

The authorities of the PRIMAS (2013) project classified drawbacks in the application of inquiry-based learning into three types. The first type was drawbacks identified in school systems. This problem was related to schools' inability to implement inquirybased learning as a learning method. Although some schools were able to adopt this method, problems arose in bridging the gap between the fixed time for instruction and assessment. However, Dorier and Maab (2012) showed that curricula in European countries supported the implementation of inquiry-based learning. The PRIMAS project (2013) indicated a gap between intended curricula and the perceptions of teachers in classes. In this instance, teachers were influenced by the assessment of practice rather than learner's acquisition of knowledge. For the second type, the literature portrays a lack of sufficient curricula or systems for appropriate application of inquiry-based learning. Teachers did not have access to training courses for the application of the inquiry-based learning method or were not able to attend necessary workshops in the originating countries that developed this methodology. This fact includes teachers and learners in third-world countries who are often unable to gain access to the proper support from their institutions to attend training courses or curricula designed to instruct in inquiry-based participation (Dorier \& Maab, 2012). Therefore, the lack of an environment to support the implementation of inquiry-based learning results in the continued use of traditional learning as the dominant learning method.

For the third type, the primary challenge in applying inquiry-based learning is within that of the facilitator's role (teacher) who should act as a guide to the learning process. Recent studies identified a psychological factor regarding teachers' roles during the application of inquiry. Keys and Bryan (2001) noted that inquiry aims to change the teacher's role from one of adopting a traditional standard method of learning into a newer, more complex method. These issues require further exploration as to how teachers might be supported in managing this transition. Additionally, teachers may feel uncomfortable in undertaking this process or might not be confident in changing their role from that of the controller to the facilitator (Keys \& Bryan, 2001). Edelson, Gordin, and Pea (1999) investigated the faults encountered during the application of inquirybased learning in a quantitative study consisting of 353 students and covering four generations of software and curricula between 1992-1996. Their study highlighted several challenges to the process of implementing inquiry-based learning, noting five main drawbacks in its use as a learning method:

1. Lack of motivation: The principal element of a successful learning process is student motivation. A high-level of motivation was required in the learning process than in any other activities. Students' motivation is required to facilitate the process of increasing their interest in educational activities. This suggestion based on Krajcik, Blumenfeld, Marx, and Soloway (1994) opinions motivation to be one of the three basic elements of the 'Learner-Centred Design'.

2. Students' inability to access investigative techniques: This is a crucial point that all researchers in the field of inquiry-based learning shared. Students must understand 
how to use inquiry-learning systems, and perform tasks using this new learning approach. Krajcik et al. (1998) highlighted this issue stating that there is a necessity for tools to be accessible to learners across their full range of abilities, and prior experience is another challenge of learner-centred design.

3. The practical constraints on the learning context: The traditional learning method has constraints and restrictions imposed by the availability of resources and fixed schedules, whilst this challenge does not have an effect on the process of inquirybased learning or even as a practical constraint on its application or indeed on the outcomes for students who use this method. Edelson et al. (1999) state that "Failure to work within the available technologies or fit within the existing schedule in schools will doom a design to failure" (p.400).

4. Student's background knowledge of inquiry-based learning: One of the fundamental issues to the application of inquiry-based learning in classes is developing students' knowledge for participating in the process of inquiry. Further, they should know how to create critical research questions, conduct analysis, and collect and evaluate data along with supporting documents (Edelson et al., 1999). This could be considered one of the fundamental factors in the application of inquiry-based learning.

5. Problems in managing and extending activities: Inquiry-based learning is a studentcentre method, so participants should be able to manage open-ended discussions. They should be actively involved in all areas of discussion, interruptions, and be able to add evidence and evaluation. Edelson et al. (1999) commented that students are required to manage highly complicated processes, unlike traditional learners.

Another critical investigation into the nature of the inquiry-based model was conducted by Keys and Bryan (2001). They stated that applying this model requires further investigation to fully understand inquiry-based learning, especially as teachers will need to practice this method and students will need to acquire the knowledge through its application in classes. Keys and Bryan (2001) summarised the challenges of implementing an inquiry-based model through four significant points. The first of these was concerned with teachers' understanding and beliefs about inquiry-based learning. The second was teachers' knowledge as for how to implement inquiry-based learning in the classroom environment. The third was teachers' lack of adequate practice in the implementation of inquiry-based learning; and finally, teachers were not entirely aware of how to implement the practical elements of inquiry-based learning. This could be contrasted with the findings of Anderson (2002), who stated that "the task of preparing teachers for inquiry teaching is much bigger than the technical matters ... at a level that includes central attention to beliefs and values" (p.8).

These predictions, as confirmed in the PRIMAS project (2013), were that the most challenging issue in applying inquiry-based learning depends on the teacher's values and beliefs. The challenge here can be summarised as one of the teachers considering their role as being the source of knowledge in the classroom, which is more natural than one of being facilitators who 'merely' manage the classroom. This fact notwithstanding, there are other scholars in the field of learning who have noticed and debated the various classifications of inquiry drawbacks. They assumed the ability to use the challenges to 
inquiry-based learning to develop other learning models (Dorier \& Maab, 2012). However, the findings of the PRIMAS project painted an overall positive picture for implementing inquiry-based learning in Europe, but it identified the major defect within the variety of applications and the usability of inquiry-based learning methods in classrooms. Furthermore, this project raised the opportunity to improve teacher performance in the application of this learning method. The project highlighted that science teacher used inquiry-based learning more than mathematics, due to the nature of real material practice. In fact, some science teachers are entirely convinced that inquirybased learning method motivates learners more than other methods of learning (Duschl, 2003).

The value of implementing inquiry-based learning in classes argued in previous literature, especially after the calls for reform in higher education. Comparative studies have been carried out on the impacts of traditional learning and inquiry-based learning in higher education. Gormally et al. (2009) studied the nature of the inquiry-based model in comparison to the traditional. Their study was based on quantitative data from 72 laboratory sessions, running over two semesters between 2006-2007, for two hoursper-week. It involved 1300 students who were divided into two groups: the first group adopted traditional learning, while the second group adopted inquiry-based learning. The study found that students' literacy and skills improved by implementing inquirybased laboratory instructions. Gormally et al. (2009) measured the changes in science literacy, process skills, and student self-confidence and scientific writing through engagement and observing learners' engaging in a science course. Gormally et al. (2009) compared the acquisition of skills and self-confidence gained by implementing inquiry-based learning laboratories to those who used a traditional learning approach. The study identified reduced outcomes for inquiry-based learners with a higher level of confidence, whereas the traditional students' gains were higher with lower confidence in their outcomes.

The application of inquiry-based learning is supposed to have pedagogical implications, and present a more attractive teaching environment in which to learn. However, students of inquiry-based learning laboratories have been found to experience a sense of complexity and frustration in practice. They were able to complete their scientific experiments and practices without any involvement from the teacher. This may help to explain the widespread resistance from students to inquiry-based learning curricula as highlighted by students during interviews. This study leads a new critical view on learners' outcomes. It identified better outcomes in traditional learning than inquirybased learning. Participants' interviews identified that learners were not interested in being involved in the learning process, as "I prefer it [the traditional lab]. I prefer just going in, looking at notes, taking a quiz and then having [the] procedure, this, this, and this. I think that's easier. But I wouldn't learn as much" (p. 12). The objectives of the study were stated clearly as being "to examine whether students acquired skills of understanding and planning investigations? Are they able to relocate this ability to real life activities? Whether they had a high level of self-confidence in these abilities" (Gormally et al., 2009, p. 4). 
Recent criticism on the prospect of inquiry-based learning was made by Lazonder and Harmsen (2016). This criticism was related to the lack of information and detail as to the role of teachers in processing and presenting them to learners accompanied with knowledge during the process of learning. Furthermore, researchers inquired about the required type of guidance to ensure a proper learning process. This issue had not been previously reported in the literature, so they conducted a study by synthesising the results of 72 studies on types of guidance and their effects, as based on different ages of learners. The authors noted that essential elements have to be considered for future investigations, such as; guidance typology, which affects the process of learning and the teacher's role in motivating learners. Furthermore, different ages have been included in their meta-analysis. The results did not indicate any connection between the age of participants and their learning outcomes. They tried to suggest a solution to the problem of the required teacher guidance by identifying the guidance required at every educational level. Lazonder and Harmsen (2016) concluded that useful guidance could facilitate knowledge acquisition, learners' performance and learning outcomes. It continued with a debate as to whether inquiry-based learning is an effective learning method without proper guidance being identified for each learning process. Their argument was based on the idea that inquiry ignores the limitations of working memory for each participant and it will decrease their capacity to store novel information in longterm memory (Ericsson \& Simon, 1980).

After all, studies for the current review and many other studies that were not identified the limitations to both traditional and inquiry-based models. The current work and previous surveys illustrate a significant gap between learner's knowledge, skills, performance and expected outcomes of adopted learning methods, especially in the practical model of inquiry-based learning in comparison to previous traditional learning methods. Appendix (B) shows the current growing demand for assessing and developing learning models. The variety in learners' performance and teachers' role as well as developing learners' outcomes, skills and background knowledge leads the current review to re-evaluate those learning models and summarise their pedagogical criteria in Table 2.

Table 2

Pedagogical criteria of key learning models.

\begin{tabular}{rlll}
\hline No. & \multicolumn{1}{c}{ Description } & \multicolumn{1}{c}{ Traditional Learning } & \multicolumn{1}{c}{ Inquiry Learning } \\
\hline 1 & Theoretical Perspective & Cognitive behaviourism & Cognitive constructivism \\
\hline 2 & Teacher Role & Dominant role & Guidance \& facilitator \\
\hline 3 & Knowledge Level & Limited knowledge & Developed knowledge \\
\hline 4 & Skills & Limited skills & Develop skills \\
\hline 5 & Confidence Level & Low confidence & High confidence \\
\hline 6 & Motivation & High motivation & Low motivation \\
\hline 8 & Performance & Low performance & High Performance \\
\hline
\end{tabular}

\section{CONCLUSION}

The literature showed that over years in which the traditional model has been implemented in the field of learning, it had encountered some drawbacks that affected 
learners' acquisition of knowledge and learning outcomes, especially after the recent technological revolution. This finding favoured the implementation of new learning models as a replacement that would contribute in changing the nature of the learning to be student-centred, rather than teacher-centred. One of those models was the inquirybased learning model. This reform in the field of learning followed by investigations and studies for assessing learning models regarding their efficiency in various fields of knowledge. Prominent examples of those investigations in the current review were implemented by Gibson and Chase (2002), the American National Research Council (2007) and the PRIMAS project (2013) in Europe.

This review has contributed to the analysis and evaluation of traditional and inquirylearning model roles as based on the relevant literature. It concluded that traditional and inquiry-based models were efficient learning models in certain conditions. However, the current technological revolution, investigations, and changes in curricula require significant reform in learning methods. Studies in the literature identified vital drawbacks to both the traditional and inquiry-based models that affect their efficiency. Whereas, traditional learning model encountered drawbacks in learner's knowledge, skills, competence and outcomes, the inquiry-based model encounters serious drawbacks in terms of its application and function. Inquiry-based learning drawbacks during application were related to school systems, curricula and the role of teacher, while, functional drawbacks were related to learners such as motivations, learners' ability to use technology, background knowledge of inquiry-based learning and managing learning activities. These drawbacks affected the productivity of the triangulated relationship between learner, teacher and learning model. Moreover, researchers highlight problems related to the literacy and self-confidence in learners' outcomes, which were described as unsatisfactory results for current learning models (Sundberg et al., 2005).

In conclusion, the current gap between learning models and the expectations of our educational systems about learners required proper reform in the field of learning by formulating new learning model, which enables to bridge this gap. Furthermore, the current review encourages researchers to investigate genuine learning methodologies that can contribute in overcoming the drawbacks identified in both the traditional and inquiry-based models. This mooted new model has to develop learners' cognition, skills, background knowledge and achieve a better level of outcomes. In addition, it has to reconsider the role of the triangulated relationship between developing learners' knowledge, the learning model and teachers' role in class that might contribute to supporting learners' confidence in their outcomes in accordance with their practice.

\section{REFERENCES}

Alousque, \& Negro, I. (2010). Cultural domains: Translation problems. Revista de Lingüística y Lenguas Aplicadas, 4(1), 137-145.

Anderson, R. D. (2002). Reforming science teaching: What research says about inquiry. Journal of Science Teacher Education, 13(1), 1-12. 
Austin, K., Orcutt, S., \& Rosso, J. (2001). How people learn: Introduction to learning theories. The Learning Classroom: Theory Into Practice-A Telecourse for Teacher Education and Professional Development.

Badawi, M. F. (2008). Investigating EFL Prospective Teachers' Ability to Translate Culture-Bound Expressions. Online Submission.

Baker, M. (2011). In other words: A coursebook on translation: Routledge.

Barrow, L. H. (2006). A brief history of inquiry: From Dewey to standards. Journal of Science Teacher Education, 17(3), 265-278.

Bereiter, C., \& Scardamalia, M. (1993). Surpassing ourselves. An inquiry into the nature and implications of expertise. Chicago: Open Court.

Biggs, J. (1996). Enhancing teaching through constructive alignment. Higher education, 32(3), 347-364.

Borenstein, M., Hedges, L. V., Higgins, J., \& Rothstein, H. R. (2009). References: Wiley Online Library.

Brown, P. C., Roediger, H. L., \& McDaniel, M. A. (2014). Make it stick: Harvard University Press.

Catford, J. C. (1965). A linguistic theory of translation: Oxford University Press.

Council, N. R. (2000). Inquiry and the national science education standards: A guide for teaching and learning: National Academies Press.

Council, N. R. (2007). Taking science to school: Learning and teaching science in grades $K-8$ : National Academies Press.

Cruz, M., \& Duff, O. B. (1997). Learning a Second Culture: The Context of Our Classrooms (Rainbow Teachers, Rainbow Students). English Journal, 86(3), 89-90.

Dixon-Woods, M. (2010). Systematic reviews and qualitative methods. Qualitative research, 331 .

Dorier, J., \& Maab, K. (2012). The PRIMAS Project: Promoting Inquiry-Based Learning (IBL) in Mathematics and Science Education across Europe PRIMAS Context Analysis for the Implementation of IBL: International Synthesis Report PRIMASPromoting Inquiry-Based Learning in Mathemati (Vol. 1). Lokaliseret på: www. primasproject. eu/servlet/supportBinaryFiles.

Duschl, R. (2003). Assessment of inquiry. Everyday assessment in the science classroom, 41-59.

Edelson, D. C., Gordin, D. N., \& Pea, R. D. (1999). Addressing the challenges of inquiry-based learning through technology and curriculum design. Journal of the Learning Sciences, 8(3-4), 391-450.

Entwistle, N., \& Tait, H. (1995). Approaches to studying and perceptions of the learning environment across disciplines. New Directions for Teaching and Learning, 1995(64), 93-103. 
Ericsson, K. A., \& Simon, H. A. (1980). Verbal reports as data. Psychological review, 87(3), 215.

Farkas, R. D. (2003). Effects of traditional versus learning-styles instructional methods on middle school students. The Journal of Educational Research, 97(1), 42-51.

Gibson, H. L., \& Chase, C. (2002). Longitudinal impact of an inquiry-based science program on middle school students' attitudes toward science. Science Education, 86(5), 693-705.

Gormally, C., Brickman, P., Hallar, B., \& Armstrong, N. (2009). Effects of inquirybased learning on students' science literacy skills and confidence.

Gough, D. (2007). Weight of evidence: a framework for the appraisal of the quality and relevance of evidence. Research papers in education, 22(2), 213-228.

Hall, T. (2002). Differentiated instruction. Wakefield, MA: National Center on.

Higgins, J., \& Green, S. (2009). Cochrane handbook for systematic reviews of interventions. London: The Cochrane Collaboration.

Hussain, A. E., \& Khuddro, A. (2016). English Arabic cultural effect in translation: A relevance theory perspective.

Johnson, D. W. (1991). Cooperative Learning: Increasing College Faculty Instructional Productivity. ASHE-ERIC Higher Education Report No. 4, 1991: ERIC.

Keeley, P., \& Eberle, F. (2008). Uncovering student ideas in science: Another 25 formative assessment probes (Vol. 3): NSTA press.

Keselman, A. (2003). Supporting inquiry learning by promoting normative understanding of multivariable causality. Journal of Research in Science Teaching, 40(9), 898-921.

Keys, C. W., \& Bryan, L. A. (2001). Co-constructing inquiry-based science with teachers: Essential research for lasting reform. Journal of Research in Science Teaching, 38(6), 631-645.

Khalaf, B. (2014). The Contextual Effects in Translating Cultural Expressions: Translation of Cultural Expression by Novice Translators. 28, 1-104.

Kiraly, D. (2017). Project-based learning: A case for situated translation. Meta: Journal des traducteursMeta:/Translators' Journal, 50(4), 1098-1111.

Knowles, M. (1973). The adult learner: a neglected species.

Krajcik, J., Blumenfeld, P., Marx, R., Bass, K., Fredricks, J., \& Soloway, E. (1998). Inquiry in project-based science classrooms: Initial attempts by middle school students. Journal of the Learning Sciences, 7(3-4), 313-350.

Krajcik, J., Blumenfeld, P. C., Marx, R. W., \& Soloway, E. (1994). A collaborative model for helping middle grade science teachers learn project-based instruction. The elementary school journal, 94(5), 483-497.

Lazonder, A. W., \& Harmsen, R. (2016). Meta-analysis of inquiry-based learning: Effects of guidance. Review of educational research, 86(3), 681-718. 
María, R., \& Luisa, R. (2016). A Review of the Traditional and Current Language Teaching Methods.

Mayer, R. (1987). Educational psychology: A cognitive approach: Scott Foresman \& Co.

Olk, H. (2003). Cultural knowledge in translation. ELT Journal, 57(2), 167-174.

Pedaste, M., Mäeots, M., Leijen, Ä., \& Sarapuu, T. (2012). Improving Students' Inquiry Skills through Reflection and Self-Regulation Scaffolds. Technology, Instruction, Cognition \& Learning, 9.

Pedaste, M., \& Sarapuu, T. (2006). Developing an effective support system for inquiry learning in a Web-based environment. Journal of Computer Assisted Learning, 22(1), 47-62.

Penrose, A. M., \& Geisler, C. (1994). Reading and writing without authority. College Composition and Communication, 45(4), 505-520.

Pi, K. D. (2010). The First One Hundred Years (3 ed.). Indianapolis, Indiana: International Honor Society in Education.

Piaget, J. (2013). Principles of genetic epistemology: Selected works (Vol. 7): Routledge.

Rashty, D. (1999). Traditional learning vs. eLearning. Dostopno na.

Sampson, V., Grooms, J., \& Walker, J. P. (2011). Argument-Driven Inquiry as a way to help students learn how to participate in scientific argumentation and craft written arguments: An exploratory study. Science Education, 95(2), 217-257.

Schauble, L., Glaser, R., Duschl, R. A., Schulze, S., \& John, J. (1995). Students' understanding of the objectives and procedures of experimentation in the science classroom. The journal of the Learning Sciences, 4(2), 131-166.

Schoenfeld, A. H. (1999). Looking toward the 21st century: Challenges of educational theory and practice. Educational researcher, 28(7), 4-14.

Sundberg, M. D., Armstrong, J. E., \& Wischusen, E. W. (2005). A reappraisal of the status of introductory biology laboratory education in US colleges \& universities. The American Biology Teacher, 67(9), 525-529.

Van Hook, S. J., \& Huziak-Clark, T. L. (2008). Lift, squeeze, stretch, and twist: Research-based inquiry physics experiences (RIPE) of energy for kindergartners. Journal of Elementary Science Education, 20(3), 1-16.

Walker, M. D. (2007). Teaching inquiry-based science - a guide for middle and high school teachers.

Watson, M. (2008). Inquiry based learning and university geography teaching. Technical Report.

Wolf, S. J., \& Fraser, B. J. (2008). Learning environment, attitudes and achievement among middle-school science students using inquiry-based laboratory activities. Research in science education, 38(3), 321-341. 